\title{
Futuro e liberdade: o trabalho e a instituição escolar nas representações sociais de adolescentes
}

\author{
Denize Cristina de Oliveira \\ Celso Pereira de Sá \\ Universidade do Estado do Rio de Janeiro \\ Frida Marina Fischer \\ Ignez, Salas Martins \\ Liliane Reis Teixeira \\ Universidade de São Paulo
}

\begin{abstract}
Resumo
Este estudo objetivou a análise das relações estabelecidas entre o trabalho do adolescente e o processo de escolarização, em duas cidades de São Paulo, apoiado na teoria das representações sociais. Foram pesquisados 778 adolescentes, trabalhadores e não trabalhadores, com idades entre 11 e 18 anos, que freqüentavam as escolas públicas das localidades, no período de 1998 a 2000. Foram realizados 18 grupos focais e a coleta de evocações livres. Para a análise de conteúdo dos grupos focais foi utilizado o software ALCESTE 4.5; as evocações livres foram analisadas a partir da teoria do núcleo central. Os resultados indicam que a relação trabalho-escola está estruturada numa relação de contradição entre as dimensões moral, de saber e das conseqüências do trabalho, permeadas pela possibilidade e pela impossibilidade de futuro. Como conclusão observou-se que, apesar do trabalho representar um risco para a escolarização, este é legitimado pelas representações dos próprios jovens, ora justificando-o, ora legitimando-o.
\end{abstract}

Palavras-chave: Trabalho do Adolescente, Instituição Escolar, Representação Social, Exclusão Social.

\begin{abstract}
Future and freedom: The work and the school institution in the social representations of adolescents. The social representations of elementary and high school students were characterized in two Brazilian towns, during 1998-2000 years. The aim of this study is the analysis of the consequences of work among adolescents to their education. Data of free-evocation about work and education among 778 students, ages 11-18 years old were collected. Among the participants, 18 focus groups were chosen according to age and job status. The software ALCESTE 4.5, EVOC 1998 and SIMI 95 were used to perform lexical, free evocation and similitude analysis, respectively. Results showed students have different conceptions regarding the potentiality of the school as an institution. The school is perceived as a "pedagogic locus" or the "only choice to have a better way of life". In the former way, the school represented a place of promotion of human development, and in the latter, a function of social inclusion/ exclusion. Working at early age is a risk of school exclusion, despite of being legitimated by youth's representations, sometimes accepting and justifying it.
\end{abstract}

Key words: Adolescent's work, School institution, Social representations, Social exclusion.

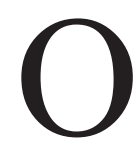

trabalho da criança e do adolescente tem se apresentado como um dos mais graves e controvertidos problemas de Saúde Pública na atualidade. Apesar de não se caracterizar como fato novo, o trabalho precoce apenas nas duas últimas décadas passou a se colo- car como um problema social, deixando seu espaço naturalizado de fato cotidiano e passando a ocupar o status de problema.

Em função dessa problematização, novos estudos começaram a se ocupar de aspectos mais propriamente econô- 
micos associados ao tema, no entanto, como problema social novo, o trabalho precoce coloca-se como importante objeto para o estudo das representações sociais já que, por hipótese, a mudança no "status social" da questão poderá condicionar a transformação das práticas sociais sobre o tema, o que poderá gerar mudanças nas representações (Sá, 1998a).

A controvérsia apontada diz respeito ao fato de, por um lado, profissionais da saúde, educadores, psicólogos e especialistas em segurança do trabalho apontarem os danos potenciais que o trabalho precoce pode causar ao crescimento e ao desenvolvimento da criança, no que tange aos aspectos bio-psicossocial e ao atraso na escolarização, devido à repetência e evasão escolar; e por outro, a própria comunidade onde estão inseridos os menores trabalhadores interpretar o trabalho infantil e do adolescente como positivo para a formação educativa do cidadão (Oliveira, 2000). É senso comum entre pais, professores e outros grupos que, mantendo a criança ocupada, evita-se que a mesma se perca nas ruas vitimada pelo consumo de drogas e por outros problemas aos quais se torna exposta. Também, o trabalho do menor com freqüência coloca-se como fundamental para o orçamento de uma família trabalhadora, geralmente pauperizada.

No entanto deve-se destacar que, mesmo entre especialistas, essa questão não pode ser considerada consensual, uma vez que os estudos sobre os impactos do trabalho precoce na saúde física, especialmente no crescimento físico e no desenvolvimento da linguagem, da capacidade lúdica, da afetividade, da socialização, dentre outras, ainda são poucos e inconclusivos (Alessi \& Navarro, 1996; OMS, 1987; Sampaio \& Ruiz, 1996).

Parte-se, neste trabalho, da premissa segundo a qual para a compreensão de uma dada realidade é necessário identificar a maneira como os sujeitos sociais identificam, explicam e elaboram essa situação. No caso de crianças e adolescentes essa realidade está em elaboração, ou seja, apesar de considerados como seres em desenvolvimento, já vivenciam realidades sociais penosas, como o trabalho precoce. O produto desse processo de retradução da realidade cotidiana são as representações sociais.

O conceito de representação social apresenta-se como elemento central desta proposta de estudo, nessa medida, reconhece-se a existência de uma forma específica de saber, caracterizado como conhecimento do senso comum, que será a via de acesso para o conhecimento de uma faceta psicossocial da situação de educação e de trabalho infantil e adolescente nos municípios estudados.

A noção de representação social, adotada neste trabalho, corresponde à teoria inaugurada por Serge Moscovici em 1961 (Jodelet, 1989a, 1989b; Moscovici, 1976, 1986). Abric (1987) avança nas tentativas de uma definição das representações sociais, destacando a subjetividade e o caráter social das representações, ao afirmar que entende-se por representações sociais o conjunto organizado de informações, atitudes, crenças que um indivíduo ou um grupo elabora a propósito de um objeto, de uma situação, de um conceito, de outros indivíduos ou grupos apresentando-se, portanto, como uma visão subjetiva e social da realidade (p. 64).

Podendo ser pensada como forma de expressão da cultura nas mudanças sociais, ou expressão do inconsciente e da ideologia nas condutas, ou ainda, conforme Bourdieu (1992), como forma de restituir à subjetividade sua objetividade, passando a ser uma forma privilegiada de pensar a relação entre o material e o mental na evolução da sociedade, o trabalho aqui apresentado coloca-se no rol daqueles que abordam as representações como processo social e particular, na medida em que as concebe como um dado concreto da realidade, delimitado no tempo e no espaço, guardando especificidade em função do contexto onde se formam.

Acredita-se, ainda, que as representações se concretizam e transformam a partir da ação, mesmo comportando contradições entre o pensamento e as práticas. Privilegia-se, dessa forma, o processo social no qual as representações se formam e se transformam, considerando a função reprodutivista da ideologia em ações e seus mecanismos cognitivos (Oliveira, Alvarenga \& Siqueira, 1998).

Cabe considerar que o estudo das representações sociais sobre o trabalho e suas conseqüências para a educação e o desenvolvimento infantil, tem como pressuposto que práticas e representações estão estreitamente associadas numa relação dialética de determinação (Abric, 1994; Martin \& Royer-Rastoll, 1990). O conhecimento das representações sobre esse processo resultará num mapeamento da realidade simbólica vivida por um dos principais agentes desse processo - a criança e o adolescente - e também aos determinantes das práticas de legitimação ou rejeição do trabalho, efetivadas pelos sujeitos estudados.

\section{Metodologia}

Esta pesquisa objetivou a análise das relações estabelecidas entre o trabalho infanto-juvenil e o processo de educação formal de crianças e adolescentes, a partir da descrição do conteúdo e análise da estrutura das representações sociais de alunos trabalhadores e não-trabalhadores. Escolheu-se um universo de sujeitos na faixa etária de 11 a 18 anos, estudantes de quinta a oitava série do ensino fundamental e de primeira a terceira série do ensino médio, inseridos nas escolas dos municípios de Monteiro Lobato e Santo Antônio do Pinhal - São Paulo.

A coleta de dados foi realizada com a aplicação de 778 questionários para a caracterização social dos respondentes e coleta de evocações livres sobre os temas indutores: "estudar", "trabalhar e estudar", "trabalho", "criança que traba- 
lha”, conforme proposto por De Rosa (1988). Parte dos jovens entrevistados participaram da realização de 18 grupos focais, compostos por alunos trabalhadores e não-trabalhadores, e organizados em função das faixas etárias de 11 a 14 anos e 15 a 18 anos; contando com 10 participantes por grupo, e direcionados para a discussão do tema "A escola, o trabalho e o futuro".

A análise de dados foi realizada com base na teoria geral das representações sociais (Di Giacomo, 1981; Doise, Clemence \& Lorenzi-Cioldi, 1992; Jodelet, 1989b), e da teoria do núcleo central (Abric, 1987, 1994; Flament, 1987), a partir das quais procurou-se descrever os elementos constituintes da representação (ou seu conteúdo), e identificar a posição ocupada pelos mesmos na estrutura representacional (elementos centrais e periféricos) (Sá, 1996).

O estudo do conteúdo da representação foi efetuado a partir da análise do material discursivo produzido nos grupos focais, separados em dois grupos etários conforme a coleta de dados, realizada pelo software Alceste 4,5 (Camargo, 1998; Lebart \& Salem, 1988; Reinert, 1990). O software Alceste informa a distribuição do texto analisado em classes lexicais, resultantes de uma análise hierárquica descendente realizada a partir das formas reduzidas originadas das palavras constantes do texto e do seu contexto semântico, bem como a associação dos perfis discursivos às variáveis sócio-econômicas informadas. A interpretação dessas classes resulta em temas que devem ser submetidos a uma leitura teórica em função do interesse do pesquisador e das relações evidenciadas.

A identificação da estrutura da representação foi efetuada a partir da utilização das técnicas de quadro de quatro casas, que possibilita a distribuição dos termos evocados em função de dois critérios - a freqüência e a ordem da evocação (Flament, 1986a; Vergès, 1998, 1992, 1984); e de análise de similitude (Degenne, 1985; Degenne \& Vergès, 1973; Flament, 1981, 1986b; Grize, Vergès \& Silem, 1987; Sá, 1996, 1998b). Para essas análises não foram consideradas as variáveis sócio-econômicas dos entrevistados, tendo em vista a tomada das evocações como fala consensual de um grupo social cujo traço comum é o fato de estudarem em escolas públicas de determinada região do Estado de São Paulo; e como traço distintivo serem trabalhadores e nãotrabalhadores.

\section{Resultados}

A apresentação do perfil das representações será feita considerando os temas orientadores da coleta de dados e os resultados mais relevantes. Cada tema tratado foi metodologicamente orientado objetivando a análise do campo e da estrutura das representações sociais identificadas. Esses temas foram: "A Escola e sua função social", "A exclusão escolar", "O trabalho e o futuro".

\section{Os conteúdos consensuais da representação: a escola, o trabalho, a família e o futuro}

Conforme assinalado, elegeu-se para o estudo do campo das representações, a análise de conteúdo discursivo produzido nos grupos focais. As classes lexicais resultantes das análises dos dois grupos etários foram bastante semelhantes, diferenciando-se apenas em relação a particularidades relativas ao grau de maturidade observado no segundo grupo, o que faz supor um universo representacional que não varia em função da faixa etária. Os eixos temáticos resultantes das duas análises foram: a relação trabalho/escola, as relações pessoais na escola, as relações familiares, e o futuro.

Observou-se como resultado da análise do grupo de 11 a 14 anos quatro classes temáticas. A primeira classe referese ao futuro e à relação estudo/trabalho, foi composta por $28,32 \%$ do material analisado, e não apresentou associação com variáveis. A segunda classe, denominada de relação professor-aluno, foi composta por $31,59 \%$, e não apresentou associação com variáveis. A terceira classe refere-se às relações familiares, foi composta por $27,02 \%$ do material, e também não apresentou associação com variáveis. A quarta classe representa a fala dos jovens sobre as suas características sócio-econômicas, e foi composta por $14,07 \%$ do material analisado.

Os alunos do ensino médio compuseram um segundo grupo, cuja análise resultou em cinco classes discursivas. A primeira, que trata da relação trabalho/estudo, foi composta por $16,90 \%$ do material analisado e foi associada aos grupos compostos pela primeira série. A segunda respondeu por $17,14 \%$, denominada de relação professor-aluno, apresentou associação ao município de Monteiro Lobato, a terceira série, e a maior escola do município. A terceira classe refere-se ao cotidiano escolar, respondeu por $12,38 \%$ do material e foi associada às seguintes variáveis: grupos compostos pelas segunda e terceira séries, município de Santo Antônio do Pinhal, e a escola rural. A quarta classe trata das relações familiares, foi formada por $43,81 \%$ do material e foi associada aos grupos das primeira e segunda séries. Finalmente a quinta classe, referente ao futuro, foi formada por $9,76 \%$ e apresentou associação aos grupos compostos pela segunda série.

São apresentados nas Figuras 1 e 2, os dendogramas de distribuição das classes lexicais em cada uma das análises, bem como os lexemas e as variáveis sócio-econômicas associadas a cada classe, e os indicadores quantitativos de freqüência e qui-quadrado de cada termo e variável.

As duas análises apresentadas revelam conteúdos comuns que podem ser sintetizados nas seguintes concepções, associadas ao trabalho e à escolarização:

1. Noções relativas à compreensão do futuro como resultante do esforço pessoal, traduzido pelo estudo e pelo traba- 


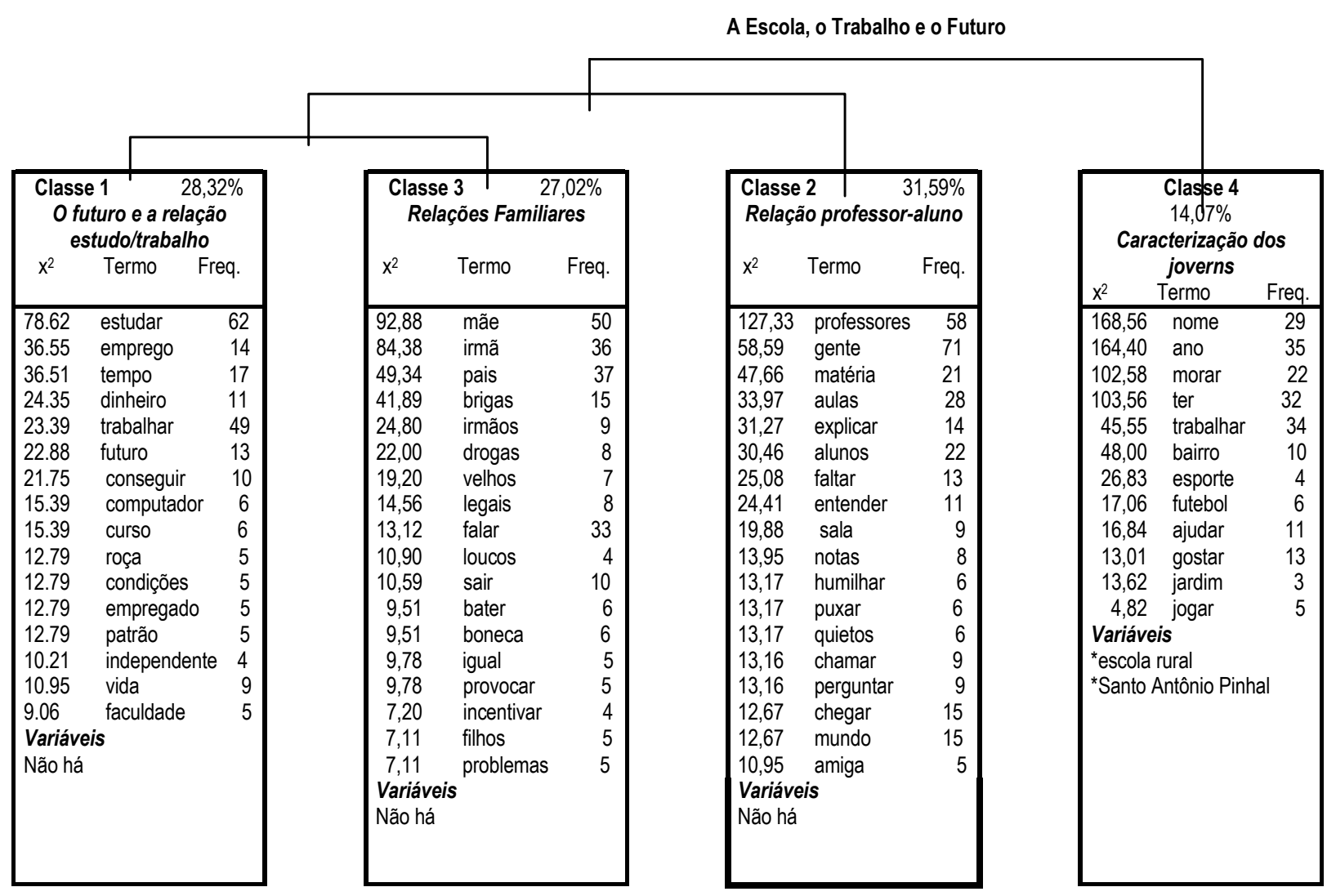

Figura 1. Perfil das classes da análise ALCESTE entre alunos de $5^{\mathrm{a}}$ a $8^{\mathrm{a}}$ série, ao tema "A Escola, o Trabalho e o Futuro". Santo Antônio do Pinhal e Monteiro Lobato, 1999.

lho, e a associação destes como fatores determinantes do futuro, na medida em que, em tese, poderiam assegurar uma melhor colocação profissional. O futuro coloca-se como um ideal a ser conquistado, em função da capacidade do jovem de assegurar a sua própria formação através da escola formal, na medida em que o grau de escolarização é reconhecido pelos jovens como pressuposto para a empregabilidade. Os jovens reconhecem as dificuldades de colocação no mercado de trabalho e atribuem à escolarização o diferencial de competitividade possível com os jovens com melhor formação.

A escola pública é tratada como um dos desafios a ser vencido, a partir do empenho dos alunos e da sua maior dedicação, como ferramentas para vencer a má qualidade de ensino oferecida. A associação do sucesso profissional ao estudo aparece referenciada à formação em nível superior, ou seja, "fazer uma faculdade" ainda representa para esses jovens o caminho para a melhoria das condições de vida, conforme pode ser observado na classe 1 da análise do primeiro grupo.

2. As contradições colocadas pelo trabalho no cotidiano são reconhecidas pelos jovens, que tentam negá-las como forma de reafirmar a possibilidade de construção do futuro. Apesar de caracterizada como "difícil", a realização das aspirações de sucesso profissional e financeiro apresenta-se como uma aspiração possível para os alunos estudados, na medida em que dêem a sua contrapartida de investimento. Não são consideradas, nas representações desse grupo, quaisquer outras variáveis que não o esforço pessoal, reafirmando, dessa forma, uma relação de determinação de tipo unicausal, característica da dimensão moral do trabalho. Na análise do segundo grupo essa questão é mais acentuada do que no primeiro, conforme pode ser observado nas classes 1 da primeira análise e classes 1 e 5 da segunda.

3. O posicionamento dos jovens quanto às relações estabelecidas entre professor e aluno fez emergir os impasses vividos em função da hierarquia rígida existente na escola e do papel de dominação do professor nessa relação, definida como de desrespeito e não escuta do aluno. O "bom professor" é referido como aquele que "é amigo, que conversa e que escuta os alunos". Configura-se, nessas falas, relações conflituosas entre professor e aluno, pautadas pela agressividade e pela falta de limites, e também o posicionamento dos alunos pela necessidade de estabelecimento de relações pautadas no respeito, tanto por parte dos alunos quanto dos professores. Este posicionamento refere-se à análise do primeiro grupo na classe 2 .

Os impasses colocados pela relação professor-aluno, observado na análise do segundo grupo, apresenta uma con- 


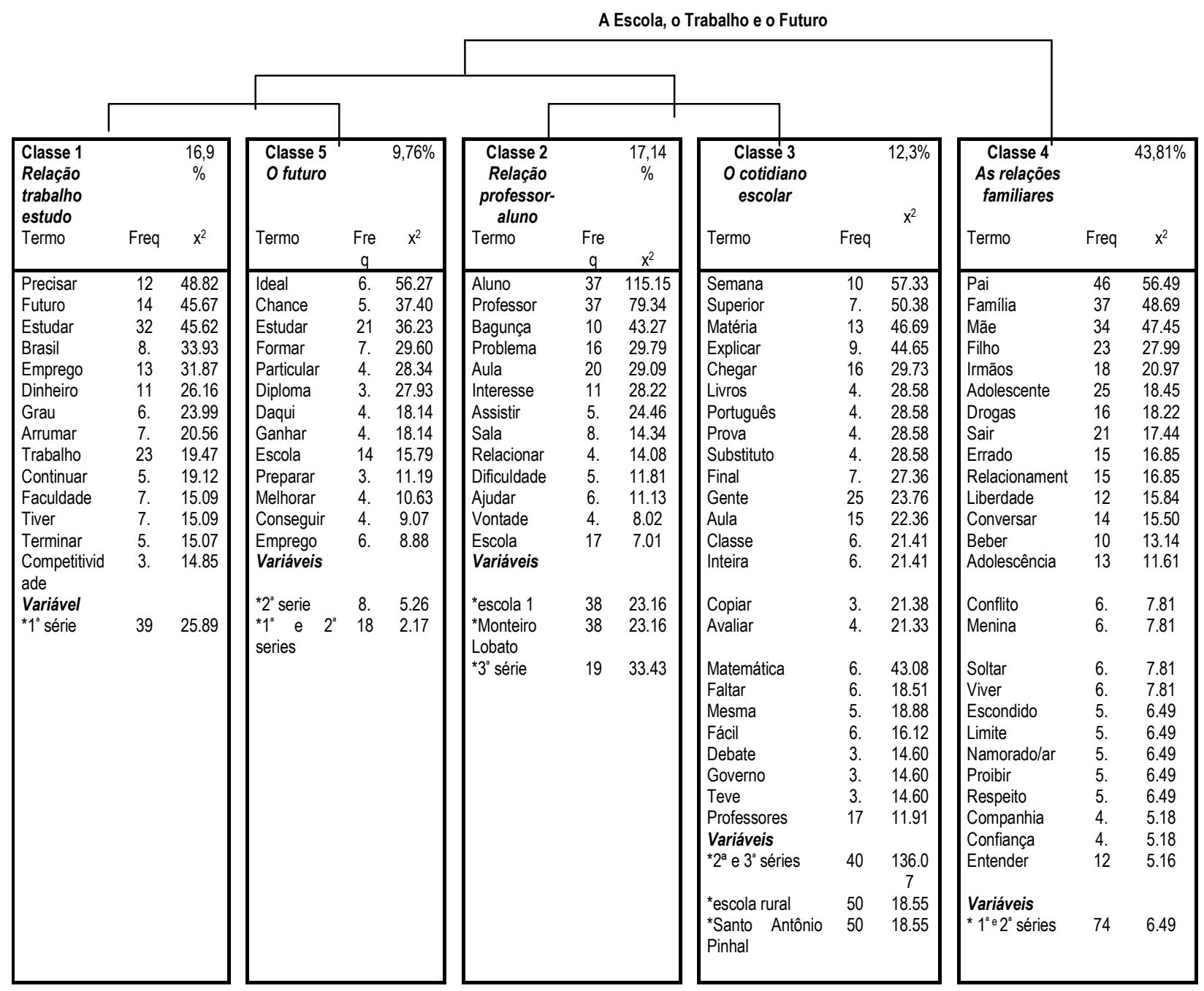

Figura 2. Perfil das classes da análise ALCESTE entre alunos de $1^{\mathrm{a}} a 3^{\mathrm{a}}$ série (ensino médio), ao tema "A Escola, o Trabalho e o Futuro". Santo Antônio do Pinhal e Monteiro Lobato, 1999.

figuração diferente do primeiro, afirmando a autoresponsabilização do aluno pelos problemas do cotidiano e pelo sucesso da escolarização. Não se observa uma relação de conflito com os professores, mas de co-responsabilização, cedendo lugar à maturidade e a uma relação de igualdade com os professores, conforme observado nas classes 2 e 3.

4. O reconhecimento das deficiências do sistema escolar e suas conseqüências para o futuro são também objeto de preocupação dos jovens. As inadequações da escola são referidas a ausências recorrentes dos professores, implicando em improvisações no ensino, deficiência de ensino da escola pública, à responsabilização do Estado pelas dificuldades do sistema escolar. Esta é uma preocupação identificada no segundo grau, nas classes 2 e 3 , não sendo referida no primeiro.

5) A família é tratada, nesta análise, em função das suas várias funções no cotidiano dos jovens, desde o estabeleci- mento das distinções de gênero, passando pela socialização na relação entre irmãos, pelos conflitos familiares e pela importância das imagens do pai e da mãe para o construção da identidade. As relações familiares são descritas pelos jovens em função do contexto próprio da faixa etária estudada. As questões tratadas especificam os posicionamentos dos jovens em função dos modelos materno/paterno vivenciados, alguns contrapondo-se ao modelo familiar e outros reforçando-o; por outro lado, observa-se a referência às drogas na vivência dos jovens e os modos diferenciais da família em lidar com o "fato novo", ora aceitando-o como indicativo de independência, ora negando-o em função dos riscos e do cerceamento social, ou ainda como tabu familiar; o terceiro aspecto a destacar na fala dos jovens refere-se à comunicação com os pais, referindo-se às dificuldades dessa relação e à sua fluência como elemento de aproximação e distanciamento do universo dos jovens, ficando aqui tam- 
bém explicitadas as diferenças em função dos costumes de cada geração. Essas relações são tratadas nas classes 3 e 4, respectivamente no primeiro e segundo grupos.

6. Entre os alunos de primeira a terceira série do ensino médio a produção discursiva sobre a escolarização e a instituição escolar reflete o seu posicionamento no mundo, na medida em que a escola coloca-se como o caminho para a construção de um futuro diferente daquele esperado em função das suas condições de classe. As relações sociais e o aprendizado para uma vida em sociedade são destacados pelos jovens como processos que também se passam na escola, não reconhecendo o espaço escolar como "locus" de aprendizagem formal apenas, mas como lugar de aprendizado da vida em sociedade.

A estrutura das representações: a escola, a familia, o trabalho e o futuro

A análise do núcleo central das representações sociais possibilita que seus elementos sejam visualizados a partir de dimensões que organizam os constituintes empíricos e categoriais, sejam eles informados pelos entrevistados ou inferidos na análise. As dimensões são entendidas como conjuntos mais estáveis apreendidos do material discursivo, que organizam e dão sentido às palavras, categorias, frases etc., agrupando elementos empíricos comuns em temas que encontram ressonância no pensamento social. As dimensões indicam, ainda, relações estabelecidas entre os termos da representação, que podem ser de diversos tipos: de determinação, de complementaridade, de especificação de atributos do objeto, entre outras.

A análise apresentada a seguir foi efetuada objetivando a identificação dos elementos que constituem o núcleo central da representação e seus elementos periféricos, bem como uma primeira tentativa de confirmação da centralidade desses termos.

\section{A educação nas dimensões de futuro e liberdade}

A educação formal, vista a partir das representações sociais, possibilita a compreensão dos elementos subjetivos que participam das práticas a ela associadas. Os resultados da análise das evocações ao termo estudar são apresentados nas Figuras 3 e 4.

Os resultados observados nas análises acima apresentadas revelam uma dimensão de futuro associada à representação dos jovens sobre a educação como elemento central. Esta refere-se à associação do estudo como elemento facilitador da ascensão social desses jovens, seja essa mobilidade social garantida por um melhor emprego ou profissão, seja assegurada por elementos abstratos como "ser alguém na vida", afirmação essa provavelmente associada ao sucesso financeiro.

A dimensão do saber é também destacada no núcleo central e associa a escola ao aprendizado, visto em diversos

\begin{tabular}{|c|c|}
\hline Freq. / Termo Evocado / Ordem de Evocação & Freq. / Termo Evocado / Ordem de Evocação \\
\hline \multicolumn{2}{|c|}{ Média Ordens Evocações = 2,04 } \\
\hline $\begin{array}{l}303 \text { bom } 1,71 \\
264 \text { aprender } 1,70 \\
64 \text { ficar inteligente } 1,86 \\
167 \text { futuro } 1,92 \\
79 \text { ser alguém } 1,97 \\
63 \text { gostoso } 1,81\end{array}$ & Freq. Média = 58,16 \\
\hline $\begin{array}{l}54 \text { ler } 1,74 \\
24 \text { conhecimento } 2 \\
42 \text { trabalho escolar } 1,95 \\
27 \text { provas } 1,78 \\
21 \text { notas } 1,71 \\
32 \text { cansativo } 1,84 \\
31 \text { chato } 2 \\
27 \text { esforçar-se } 1,93 \\
37 \text { importante } 1,78 \\
22 \text { responsabilidade } 1,86\end{array}$ & $\begin{array}{l}28 \text { ruim 2,43 } \\
43 \text { amizade } 2,33 \\
26 \text { divertido } 2,58 \\
23 \text { comportamento } 2,26 \\
19 \text { dedicação } 2,26 \\
44 \text { atenção 2,14 } \\
27 \text { sabedoria 2,37 } \\
36 \text { estudar 2,14 } \\
34 \text { educação 2,15 } \\
57 \text { bom trabalho depois } 2,35 \\
27 \text { profissão } 2,22 \\
23 \text { professor } 2,13 \\
36 \text { material } 2,14 \\
\end{array}$ \\
\hline
\end{tabular}

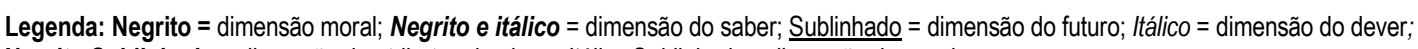

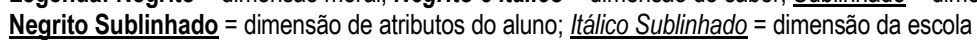

Figura 3. Análise do núcleo central ao termo indutor "estudar" entre alunos trabalhadores e nãotrabalhadores de Santo Antônio do Pinhal e Monteiro Lobato, São Paulo, 1999. 


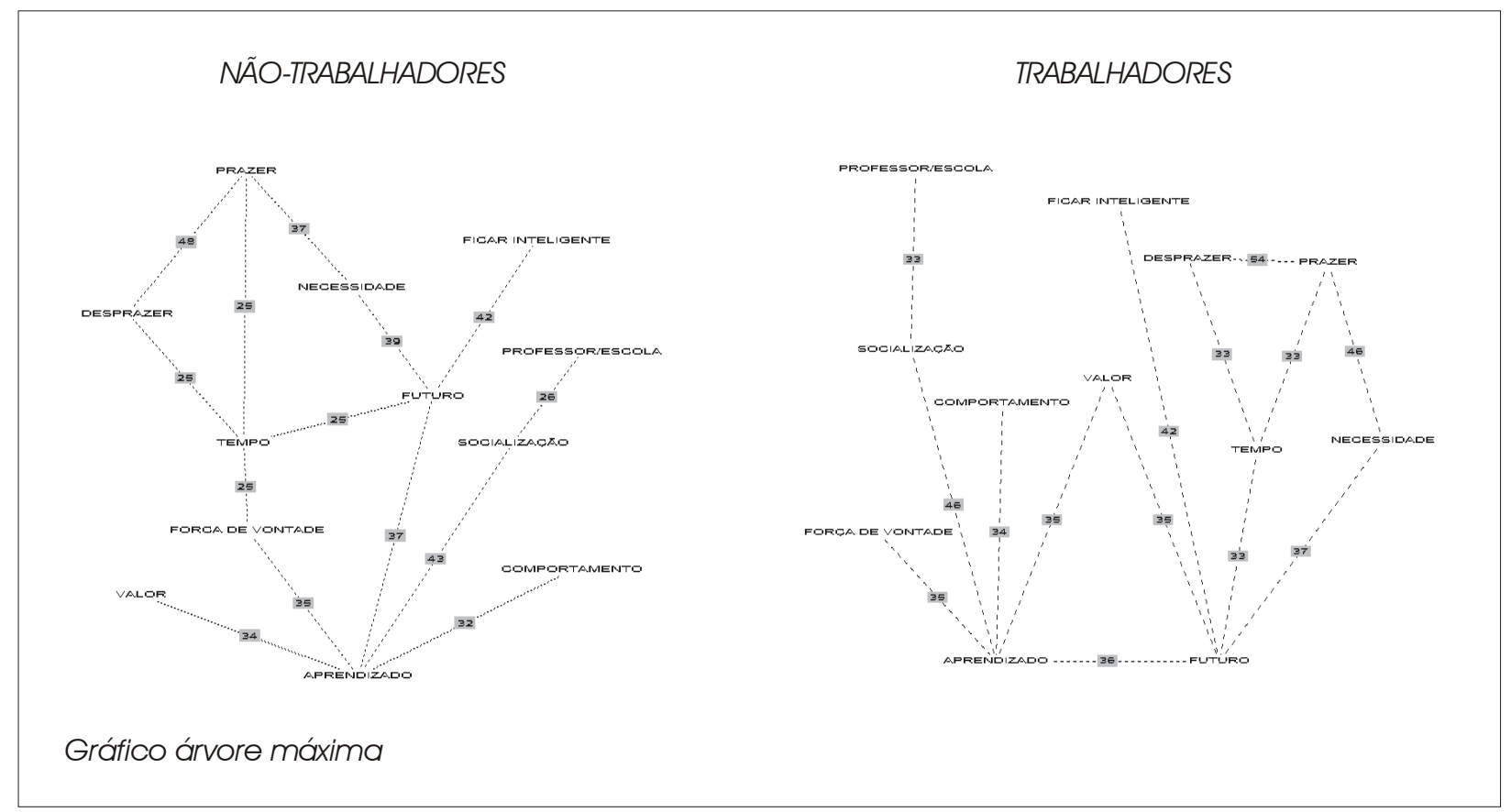

Figura 4. Análise de similitude das categorias evocadas ao termo "estudar" por alunos trabalhadores e nãotrabalhadores de Monteiro Lobato e Santo Antônio do Pinhal, SP, 1999.

planos: o aprendizado de habilidades específicas, como ler e escrever; o aprendizado de regras sociais; o aprendizado de características de desenvolvimento valorizadas socialmente, como atenção, educação e inteligência. Dessa forma, a escola é concebida pelos jovens como um locus de saber, que ora é vista como positivo e estimulante (dimensão moral), e ora é vista como ruim, desinteressante e cansativa (dimensão avaliativa).

Entre os elementos periféricos da representação, observa-se a associação da instituição escolar às dimensões de saber, de atributos individuais do aluno e de futuro, reafirmando os elementos centrais e inserindo um novo elemento especificado nos atributos individuais do aluno. Nesse nível outros elementos são destacados, tais como as relações de amizade e a infra-estrutura da própria escola, necessária ao aprendizado, como o material escolar e o próprio professor.

Por se tratar de um plano com caráter prescrito da realidade, os elementos periféricos parecem sinalizar para a função de socialização atribuída à escola, onde as dimensões de futuro, saber e moral presentes no núcleo central da representação funcionariam como elementos estáveis associados à escolarização.

Nessa análise, a escola e por extensão a aprendizagem, colocam-se como objetos de representação ancorados no plano da liberdade e do saber. O que se pode afirmar, portanto, é que esses jovens atribuem sentidos bastante claros à instituição escolar e também algumas funções: a escola parece ter o poder de libertar, possibilitando um melhor futuro; deve cumprir o papel de instância de saber, o que a vin- cula às possibilidades e impossibilidade de ascensão social de crianças e adolescentes.

A análise comparativa de alunos trabalhadores e nãotrabalhadores revela uma associação diferencial do termo aprendizado, já que entre os trabalhadores esse termo está triangulado com futuro e valor, e entre os não-trabalhadores não se observa uma triangulação, mas ligações de quatro elementos entre aprendizado - futuro - força de vontade e tempo, o que indica uma representação mais ingênua e idealizada da escolarização entre os não-trabalhadores, e uma noção explícita de valor moral associado ao estudo entre os jovens trabalhadores.

\section{A contradição nas relações trabalho-escola}

Os resultados observados na análise das evocações produzidas à expressão trabalhar-estudar são apresentados nas Figuras 5 e 6.

A análise das evocações ao termo indutor trabalhar-estudar vem reafirmar alguns conteúdos da representação sobre o trabalho, presentes entre jovens estudantes, trabalhadores e não-trabalhadores. Observa-se uma contradição caracterizada pela presença da dimensão das conseqüências do trabalho para a escolarização, tais como maior cansaço, falta de tempo para o estudo, atrapalhar o estudo etc., ao lado da dimensão moral do trabalho, associando valores ao mesmo tempo em que afirmam as vantagens associadas ao trabalho, tais como a maior maturidade do aluno trabalhador, a necessidade de construção de um futuro e o aprendizado resultante do trabalho. 


\begin{tabular}{|l|l|}
\hline Freq. / Termo Evocado / Ordem de Evocação & Freq. / Termo Evocado / Ordem de Evocação \\
\hline \begin{tabular}{|l|l|}
\hline \multicolumn{1}{|c|}{ Média Ordens Evocacões = 2,06 } \\
\hline 38 bom 1,71 & 74 responsabilidade 2,27 \\
100 esforço 1,92 & \\
259 cansativo 1,72 & \\
\hline 63 dificil 1,62 & 43 chato 2,09 \\
53 sem tempo 2,06 & 26 puxado 2,38 \\
40 atrapalha o estudo 2,05 & 55 futuro 2,42 \\
20 atrapalha 1,85 & 24 independência 2,33 \\
25 tem que estudar 2,04 & 57 necessidade 2,14 \\
64 aprender 2,03 & 26 dinheiro 2,19 \\
28 estudar 1,89 & 43 gostoso 2,26 \\
40 conciliar 2,03 & \\
31 obrigação 2,06 & \\
26 importante 2,04 & \\
\hline
\end{tabular}
\end{tabular}

Legenda: Negrito = dimensão moral; Negrito e itálico = dimensão da necessidade; Itálico = dimensão das conseqüências do trabalho;

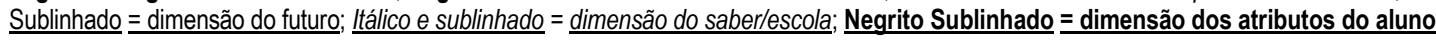

Figura 5. Análise do núcleo central ao termo indutor "Trabalhar e Estudar" entre estudantes trabalhadores de Santo Antônio do Pinhal e Monteiro Lobato, São Paulo, 1999.

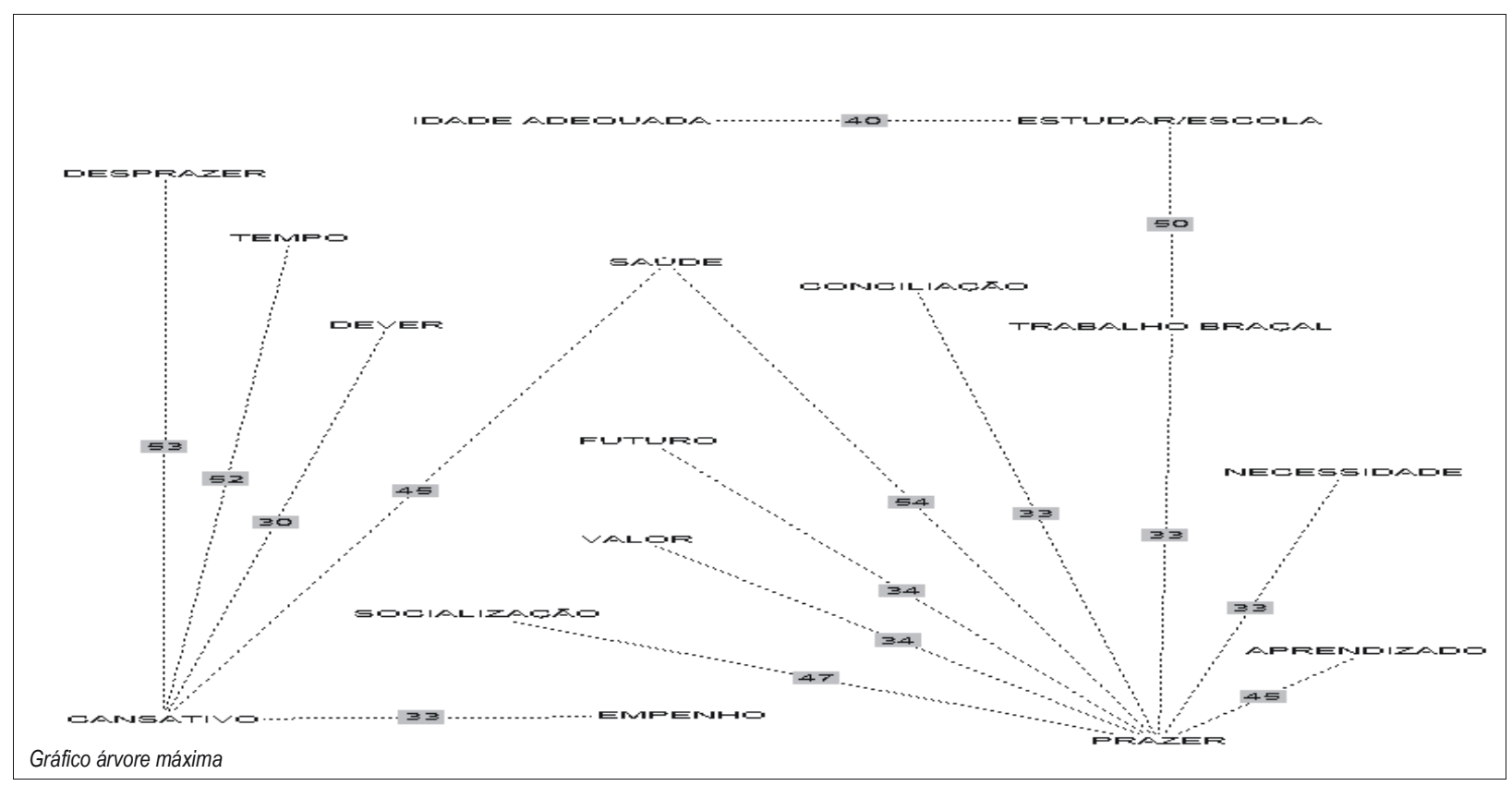

Figura 6. Análise de similitude das evocações ao tera indutor "trabalhar e estudar" por alunos trabalhadores de Monteiro Lobato e Santo Antônio do Pinhal, SP, 1999.

A complexidade das representações dos jovens estudantes, trabalhadores e não-trabalhadores pode ser evidenciada nos dados apresentados, uma vez que esses jovens posicionam-se entre a realidade do cotidiano do trabalho e seus prejuízos, e o discurso moral associado ao mesmo, que destaca os supostos benefícios a ele associados. Se nas evocações sobre o trabalho como tema isolado, conforme será apresentado a seguir, expressa-se a perspectiva de futuro como atenuante para o cotidiano do trabalho, na relação tra- balho-escola essa mesma afirmação não é possível, já que os prejuízos derivados do mesmo expressam-se como determinantes da representação.

\section{O trabalho e a criança trabalhadora: duas}

dinâmicas representacionais entre crianças e adolescentes

Buscou-se explorar, na análise das representações sociais do trabalho, as diversas posições que crianças e ado- 
lescentes podem assumir diante desse objeto, ou seja, os diversos significados em função das diferentes formas de visualizá-lo e das diferentes posições do agente que o representa: a posição de agente que tem incorporada a realidade do trabalho no seu cotidiano; a posição de observador, que encara o trabalho como problema externo, ou seja, problema esse que não faz parte da sua realidade cotidiana e é identificado apenas como realidade do outro; e finalmente, a partir da posição do observador que fala do trabalho como um tema social neutro, com o qual não guarda identificação.

A objetivação das perspectivas citadas foi efetuada através dos temas indutores trabalho e criança que trabalha, cujos resultados podem ser observados adiante.

\begin{tabular}{|c|c|c|}
\hline Freq. / Termo Evocado / Ordem de Evocação & Freq. / Termo Evocado / Ordem de Evocação & \\
\hline \multicolumn{3}{|c|}{ Média Ordens Evocações = 2,02 } \\
\hline $\begin{array}{l}219 \text { bom } 1,74 \\
121 \text { responsabilidade } 1,94 \\
101 \text { esforço 1,78 } \\
252 \text { dinheiro 1,67 } \\
90 \text { ajudar } 1,82\end{array}$ & $\begin{array}{l}216 \text { cansaço 2,04 } \\
63 \text { ruim 2,05 }\end{array}$ & 56,77 \\
\hline $\begin{array}{l}37 \text { trabalho } 1,92 \\
27 \text { importante } 1,63 \\
22 \text { obrigação } 2,00 \\
21 \text { dedicação } 1,81 \\
29 \text { salário } 1,97 \\
24 \text { profissão } 1,96 \\
15 \text { pesado } 1,73\end{array}$ & $\begin{array}{l}55 \text { futuro 2,05 } \\
41 \text { independência } 2,17 \\
21 \text { bens materiais } 2.43 \\
20 \text { com idade } 2,30 \\
29 \text { chato 2,03 } \\
14 \text { dor no corpo 2,43 } \\
14 \text { folga 2,14 } \\
26 \text { falta de diversão } 2,19 \\
27 \text { preguiça 2,07 } \\
22 \text { trabalhar 2,05 } \\
38 \text { gostoso 2,08 } \\
13 \text { interessante 2,54 } \\
49 \text { necessidade 2,06 } \\
33 \text { aprender 2,21 }\end{array}$ & \\
\hline
\end{tabular}

Legenda: Negrito = dimensão moral; Negrito e itálico = dimensão da necessidade; Itálico = dimensão das conseqüências do trabalho;

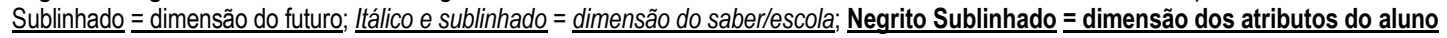

Figura 7. Análise do núcleo central ao termo indutor "trabalho", alunos não trabalhadores de Santo Antônio do Pinhal e Monteiro Lobato, 1999.

\begin{tabular}{|c|c|c|}
\hline Freq. / Termo Evocado / Ordem de Evocação & Freq. / Termo Evocado / Ordem de Evocação & \\
\hline \multicolumn{3}{|c|}{ Média Ordens Evocações $=\mathbf{2 , 0 0}$} \\
\hline $\begin{array}{l}185 \text { bom } 1,72 \\
91 \text { responsabilidade } 1,97 \\
60 \text { esforço } 1,82 \\
172 \text { dinheiro } 1,62 \\
59 \text { ajudar } 1,85 \\
66 \text { cuidar de casa } 1,94\end{array}$ & 160 cansaço 2,07 & 44,14 \\
\hline $\begin{array}{l}37 \text { necessidade } 1,97 \\
18 \text { salário } 2,00 \\
11 \text { dedicação } 1,82 \\
22 \text { importante } 1,73 \\
18 \text { trabalho } 1,89 \\
16 \text { preguiça } 1,94 \\
11 \text { pesado } 1,82 \\
19 \text { chato } 1,89 \\
20 \text { profissão } 1,95 \\
21 \text { roça } 1,95\end{array}$ & $\begin{array}{l}40 \text { futuro 2,10 } \\
29 \text { independência } 2,41 \\
15 \text { bens materiais } 2,33 \\
24 \text { aprender 2,25 } \\
20 \text { diversão 2,20 } \\
10 \text { exercício 2,10 } \\
12 \text { folga 2,17 } \\
33 \text { ruim 2,09 } \\
17 \text { obrigação 2,18 } \\
16 \text { trabalhar 2,13 } \\
35 \text { gostoso 2,06 }\end{array}$ & \\
\hline
\end{tabular}

Legenda: Negrito = dimensão moral; Negrito e itálico = dimensão da necessidade; Itálico = dimensão das conseqüências do trabalho;

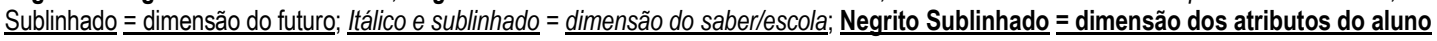

Figura 8. Análise do núcleo central ao termo indutor "Trabalho", alunos trabalhadores de Santo Antônio do Pinhal e Monteiro Lobato, 1999. 


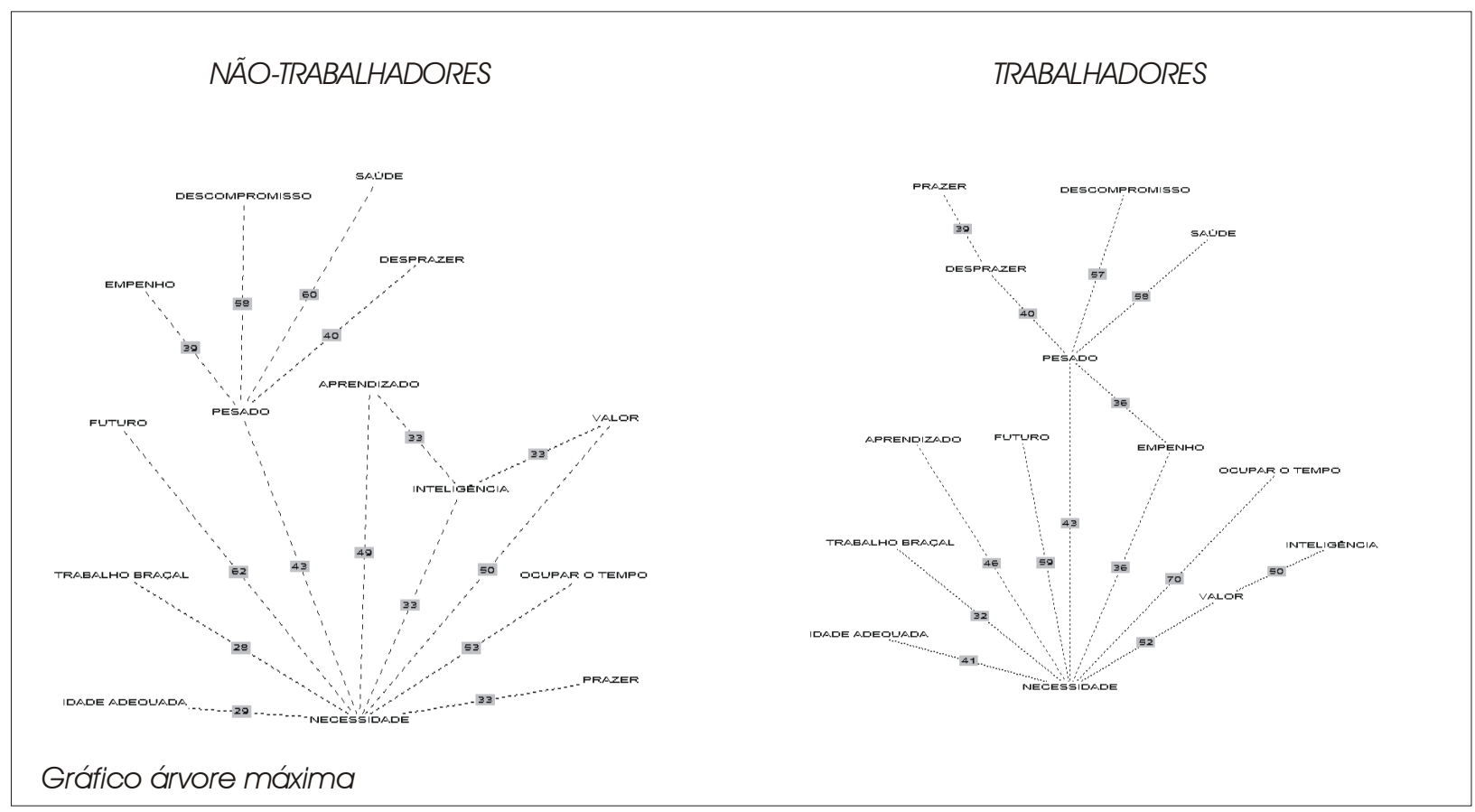

Figura 9. Análise de similitude das categorias evocadas sobre o tema indutor "trabalho" por alunos e alunostrabalhadores Monteiro Lobato e Santo Antônio do Pinhal, SP, 1999.

\section{O trabalho como objeto social: o trabalho dos outros}

O termo indutor trabalho foi simbolicamente associado pelos jovens entrevistados ao trabalho do outro, ou seja, a uma dimensão impessoal do trabalho, concebido como atividade que visa produzir riquezas e ascensão social, inclusive para as camadas mais pobres da população.

Como elemento prescritivo de uma determinada ordem social, as representações sobre o trabalho vêm acompanhadas de duas dimensões principais: um conteúdo moral, que nesta análise é destacado como um dos elementos centrais da representação, e uma dimensão de necessidade, onde o trabalho é tomado como gerador das possibilidades de sobrevivência, também participante do núcleo central.

No nível intermediário observa-se a presença de uma terceira dimensão, a das conseqüências do trabalho, presente no termo cansaço, que apresentou alta freqüência e uma ordem de evocação também importante, podendo ser considerado como confirmação do núcleo central.

Como elementos periféricos observa-se a dimensão do futuro, que reflete uma concepção de trabalho associado à ascensão social das classes populares, reafirmada em termos como futuro, independência, bens materiais e aprendizado; e a dimensão das conseqüências do trabalho, que explicita as condições concretas nas quais esse ocorre, e suas conseqüências no cotidiano dos jovens. Observa-se uma ambigüidade na periferia dessa representação, que afirma, ao mesmo tempo, uma perspectiva na qual o trabalho funci- onaria como a via lícita da mobilidade social, onde as condições de vida desfavoráveis observadas nos municípios estudados poderiam ser superadas; e outra onde as condições desfavoráveis do trabalho e a impossibilidade de superação do mesmo é reconhecida, impedindo inclusive o futuro, ao qual o trabalho, por hipótese, deveria conduzir.

Deve-se destacar que a configuração geral da representação sobre o trabalho nos grupos de trabalhadores e de estudantes não-trabalhadores é a mesma, não apresentando diferenças que sejam passíveis de uma análise comparativa, conforme poderá ser observado nas Figuras 7,8 e 9.

A análise de similitude reforça o papel organizador da representação atribuído à dimensão da necessidade, a partir da qual são irradiados os outros sentidos. Essa categoria estabelece fortes ligações com as categorias "ocupar o tempo" - associada a tirar a criança da rua e impedir a marginalidade e o envolvimento com drogas -, "valor" e "futuro". O segundo eixo irradiador da representação refere-se ao trabalho como atividade difícil, opressora, expresso na categoria "pesado", que por sua vez está associado às categorias "descompromisso" e "questões de saúde".

\section{O trabalho na sua interface com o Direito: o "trabalho da lei"}

A análise deste tema indutor diferencia-se da anterior revelando um perfil específico. A “criança que trabalha” é representada pelos jovens trabalhadores entrevistados como "o outro", o outro indivíduo, o outro ser social, o outro que é explorado, o outro que não tem direitos, tendo como 


\begin{tabular}{|c|c|c|}
\hline Freq. / Termo Evocado / Ordem de Evocação & Freq. / Termo Evocado / Ordem de Evocação & \\
\hline \multicolumn{3}{|c|}{ Média Ordens Evocações = 1,91 } \\
\hline $\begin{array}{l}232 \text { ruim } 1,72 \\
88 \text { bom } 1,81 \\
142 \text { exploração } 1,69 \\
96 \text { injustiça } 1,69 \\
83 \text { crime } 1,90\end{array}$ & & 66,68 \\
\hline $\begin{array}{ll}53 & \text { não pode } 1,77 \\
44 & \text { errado } 1,48 \\
32 & \text { coitada } 1,78 \\
36 & \text { escravidão } 1,78\end{array}$ & $\begin{array}{l}58 \text { atrapalha } 1,98 \\
60 \text { cansativo } 2,15 \\
39 \text { chato } 2,05 \\
37 \text { tem que estudar } 2,08 \\
45 \text { sem estudar } 2,22 \\
43 \text { obrigada } 2,14 \\
31 \text { perigoso } 3,03 \\
62 \text { necessidade } 1,92 \\
51 \text { ajudar } 2,16 \\
35 \text { esforçada } 1,97\end{array}$ & \\
\hline
\end{tabular}

Legenda: Negrito = dimensão moral; Negrito e itálico = dimensão da necessidade; Itálico = dimensão da responsabilização social; $\underline{\text { Sublinhado }}=\underline{\text { dimensão legal e de direitos }}$

Figura 10. Análise do núcleo central ao termo indutor "Criança que Trabalha" entre alunos não trabalhadores de Santo Antônio do Pinhal e Monteiro Lobato, 1999.

\begin{tabular}{|c|c|}
\hline Freq. / Termo Evocado / Ordem de Evocação & Freq. / Termo Evocado / Ordem de Evocação \\
\hline \multicolumn{2}{|c|}{ Média Ordens Evocações = 1,92 } \\
\hline \begin{tabular}{|l|}
158 ruim 1,70 \\
75 bom 1,80 \\
104 exploração 1,73 \\
64 injustiça 1,69 \\
61 crime 1,80
\end{tabular} & 42,74 \\
\hline $\begin{array}{ll}34 & \text { não pode } 1,65 \\
30 & \text { errado } 1,53 \\
25 & \text { coitada } 1,68 \\
18 & \text { irresponsabilidade } 1,95 \\
24 & \text { esforçada } 1,88 \\
17 & \text { Aprende } 1,94 \\
30 & \text { escravidão } 1,77 \\
42 & \text { necessidade } 1,83\end{array}$ & $\begin{array}{l}42 \text { cansativo } 2,12 \\
24 \text { triste } 2,04 \\
22 \text { crueldade } 2,04 \\
35 \text { atrapalha } 2,03 \\
22 \text { tem que estudar } 2,14 \\
31 \text { obrigada } 2,06 \\
26 \text { sem estudar } 2,27 \\
21 \text { perigoso } 2,10 \\
41 \text { ajudar } 2,20 \\
\end{array}$ \\
\hline
\end{tabular}

Legenda: Negrito = dimensão moral; Negrito e itálico = dimensão da necessidade; Itálico = dimensão da responsabilização social; $\underline{\text { Sublinhado }}=\underline{\text { dimensão legal e de direitos }}$

Figura 11. Análise do núcleo central ao termo indutor "criança que trabalha" entre alunos trabalhadores de Santo Antônio do Pinhal e Monteiro Lobato, 1999.

contrapartida uma auto-imagem do "eu não criança", "eu sujeito sem direitos" e "eu que tem no trabalho um dever". Essa auto-imagem, portanto, nega aos jovens a sua condição de crianças e adolescentes, e reflete no outro as prescrições de direito, já que o Estatuto da Criança e do Adolescente e a Campanha de Combate ao Trabalho Infantil foram amplamente socializados, inclusive entre as crianças (Diário Oficial da União, 1990).

Essa "criança trabalhadora" é representada em quatro dimensões, que predominam no núcleo central nos dois grupos - trabalhadores e não-trabalhadores. Essas dimensões são a valorativa negativa, da responsabilização social, legal e de direitos e da necessidade do trabalho.
Na dimensão valorativa negativa, o trabalho infantil é associado a um evento negativo e indesejável, caracterizado como ruim, errado, cansativo, triste e que implica numa relação de obrigatoriedade da criança com o trabalho, caracterizando-se como uma dimensão avaliativa. A dimensão da responsabilização social refere-se à associação da atividade laboral à exploração da força de trabalho da criança pelo adulto, à injustiça humana do trabalho, ao trabalho como escravidão e irresponsabilidade, ao trabalho como risco e crueldade. A dimensão legal e de direitos refere-se ao trabalho da criança como privação de direitos fundamentais, como a escolarização e o trabalho penoso; e a dimensão da neces- 


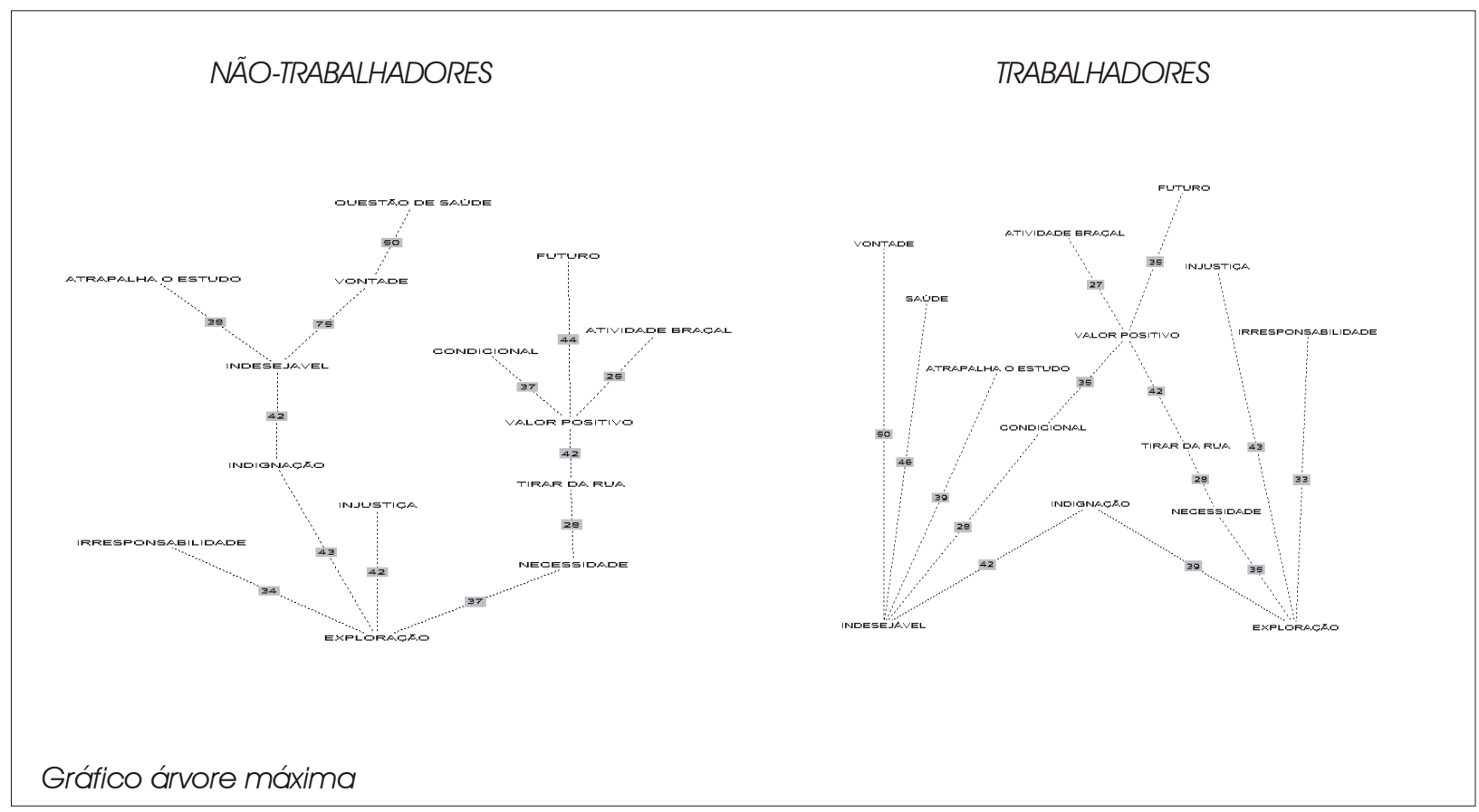

Figura 12. Análise de similitude das evocações de alunos trabalhadores e não trabalhadores sobre o tema indutor "criança que trabalha", Monteiro Lobato e Santo Antônio do Pinhal, SP, 1999.

sidade social do trabalho vincula-se à dependência econômica do mesmo.

Destaca-se que na análise deste termo indutor a maior parte das evocações produzidas rejeitam o trabalho da criança, observando-se uma completa ausência do discurso moral associado ao trabalho ou à sua interface de futuro e realização.

Os elementos periféricos destacam as mesmas dimensões já apontadas, mas com um caráter prático delimitado e alguma especificação em função dos grupos de estudantes não-trabalhadores e trabalhadores. Entre os estudantes nãotrabalhadores, revelam-se as dimensões da responsabilização social e legal e de direitos; entre os trabalhadores destacamse as dimensões da necessidade e a legal e de direitos, o que revela uma diferença indicativa de uma representação idealizada entre os não-trabalhadores, e associada à realidade, no caso dos trabalhadores, para os quais o trabalho é determinado pela necessidade econômica da família (Figuras 10, 11 e 12).

O gráfico de similitude aponta para diferenças nos grupos de trabalhadores e de não-trabalhadores. A categoria "exploração" revela-se como elemento organizador único no grupo de trabalhadores em torno do qual todos os outros se organizam, tendo como categorias diretamente associadas as da "necessidade", "injustiça", "indignação" e "irresponsabilidade". Entre os estudantes não-trabalhadores, a análise de similitude mostra uma estrutura bipolar, expressa nas categorias "indesejável" e "exploração", sendo seguidas de todas as outras.
Conforme apontado, a representação dos estudantes trabalhadores e não-trabalhadores sobre o trabalho diferenciase quando este é objetivado na criança trabalhadora, mostrando-se impregnado do discurso social legalista sobre o trabalho infantil. Esse conteúdo está, provavelmente, associado à veiculação do tema pela mídia, mas também refere-se à possibilidade de visualização do outro como um sujeito de direitos. Essa nova faceta da representação sobre o trabalho, revelada na análise comparativa dos termos indutores, pode indicar uma transformação da representação sobre o trabalho infantil entre os jovens, trabalhadores e não-trabalhadores.

\section{Considerações finais}

Considera-se, para efeito deste estudo, que as representações sociais são indispensáveis para a compreensão da dinâmica social, bem como informativas e explicativas da natureza das ligações sociais, intra e intergrupos, e das relações dos indivíduos com seu ambiente social, tornando-se assim um elemento essencial para a compreensão dos determinantes dos comportamentos e das práticas sociais, conforme proposto por Abric (1994).

Por outro lado, umas das funções primordiais do sistema educacional é o de funcionar no sentido da socialização e integração da criança ao universo cultural e simbólico da sociedade, propiciando-lhes instrumentos capazes para modificar a sua realidade (Patto, 1996).

A análise das relações estabelecidas entre o estudo e o trabalho apontam para os determinantes da exclusão do sis- 
tema escolar, revelando-se como objetos que apresentam semelhanças e nas representações dos jovens e especificidade que aponta para a exclusão.

Observa-se que se o estudo coloca-se nos planos da liberdade e do saber, o que é observado no trabalho apenas quando tomado na sua dimensão de futuro. Assim, a exclusão escolar justifica-se através da atribuição de uma dimensão moral e de necessidade bastante fortes ao trabalho.

Os jovens participantes do estudo atribuem sentidos bastante claros a cada objeto analisado e associam a eles funções distintas: se o trabalho parece funcionar como um mecanismo de legitimação de valores sociais hegemônicos, a escola parece ter o poder de libertar assegurando um futuro diferente daquele da família de origem; se o trabalho cumpre uma função associada à sobrevivência, a escola funciona como instância de saber e de criatividade; e ambos estão estreitamente ligados às possibilidades ou impossibilidade de futuro de crianças e adolescentes das camadas mais pobres da população. Assim, observa-se uma crença na escola como instituição capaz de transferir saber e de possibilitar um melhor futuro para crianças e adolescentes; e o trabalho como uma forma de reprodução de desigualdades na medida em que se impõe pela necessidade econômica das famílias e de valores sociais hegemônicos incorporados pelos jovens quando o associam a um valor moral.

Podem ser observadas duas imagens associadas ao trabalho pelos jovens estudados: uma legitimada pelo discurso moral e atenuada pela perspectiva de um futuro distinto daquele da família de origem; e outra ancorada no discurso legal, fundamentado no direito de ser criança e na indignação diante da exploração da mão-de-obra infantil.

Desta forma, as representações caracterizadas cumprem algumas funções que merecem destaque: a naturalização do trabalho precoce; a oposição ao trabalho infantil como uma entidade abstrata sem vínculo com o contexto social vivido; a justificação das relações sociais experimentadas por crianças e adolescentes através do trabalho; a prescrição de comportamentos e de práticas consideradas socialmente lícitas.

Deve-se considerar que as representações sociais podem ser vistas como elementos que facilitam as relações sociais, ou conforme afirmado por Abric (1994), o desenvolvimento das interações entre os grupos modifica as representações que os membros formam de si próprios, do seu grupo social, de outros grupos e de seus membros. Mobiliza uma atividade representativa destinada a regular, antecipar e justificar as relações sociais estabelecidas, conforme observado neste trabalho.

A análise comparativa do próprio trabalho e do trabalho do outro entre os adolescentes, demonstra a presença de diferentes representações. A criança trabalhadora não constrói uma auto-representação como tal, mas distingue duas imagens principais associadas ao trabalho infantil, conforme discutido.

Os sujeitos entrevistados negam, dessa forma, sua condição de criança através de uma forma particular de distinção entre o eu e o outro. Assim, os dados indicam múltiplas facetas assumidas pelas representações dos jovens trabalhadores, ora legitimando o trabalho sob quaisquer condições, ora opondo-se a ele ou subordinando-o às prerrogativas legais. Essa dicotomia parece cumprir uma função protetora, na medida em que falar do outro distancia os jovens trabalhadores das condições vivificadas por eles próprios no cotidiano.

Por outro lado, a representação social reflete a natureza das regras e das ligações sociais, portanto ela é prescritiva de comportamentos e de práticas, definindo o que é lícito, tolerável ou inaceitável em dado contexto social, legitimando práticas, como o observado na naturalização do trabalho infantil.

As observações finais indicam para uma tripla via de exclusão das crianças estudadas: através da pobreza, observada na dimensão da necessidade, expressa numa escola de menor qualidade, na dificuldade de acesso à pré-escola e à continuidade dos estudos após a quinta série do ensino fundamental; no acesso precoce ao mercado de trabalho, com as conseqüências de cansaço, menor capacidade de concentração e retenção escolar, expressas na dimensão das conseqüências do trabalho; e uma forma particular de "exclusão simbólica", promovida por imagens construídas por pais e também por professores e que se expressam nas representações dos jovens na dimensão da vontade, que concebe os alunos que "dão e que não dão para o estudo" e, por hipótese, seriam excluídos da escola com ou sem a presença do trabalho associado.

Essas vias de exclusão são, neste estudo, legitimadas pela associação do trabalho a um valor moral, expresso na dimensão moral do trabalho, que o concebe como valor individual e social, e como necessidade, particular e geral.

Como conclusão considera-se a necessidade de um repensar das formas de constituição das políticas de promoção de desenvolvimento local, a educação dentre elas, para a abordagem da questão do trabalho entre crianças e adolescentes, e para a análise dos seus reais impactos sobre as condições de vida desse grupo populacional. Essa reflexão implica na consideração dos mecanismos psicossociais de constituição da realidade pelos sujeitos e grupos sociais, além do papel da comunicação e da ideologia nas ações de transformação da realidade social.

\section{Agradecimentos}

Pesquisa Financiada pela FAPESP - Fundação de Amparo à Pesquisa do Estado de São Paulo, Processo 08081-6 e CAPES - Coordenação de Aperfeiçoamento de Pessoal de Nível Superior, Processo RH-SST 03/98. 


\section{Referências}

Abric, J. C. (1987). Coopération, compétition et représentations sociales. Cousset: DelVal.

Abric, J. C. (1994). Pratiques sociales et représentations. Paris: Presses Universitaires de France.

Alessi, N., \& Navarro, V. L. (1996, abril). O trabalho de crianças e adolescentes na cultura canavieira e os impactos sobre sua saúde. Trabalho apresentado na Oficina sobre Os impactos do trabalho precoce na saúde de crianças e adolescentes, Brasília, DF.

Bourdieu, P. (1992). Un progrès de la réflexivité. Préface. In W. Doise, A Clemence \& F. Lorenzi-Cioldi (Orgs.), Représentations sociales et analyses de données (pp. 2-3). Grenoble: Presse Universitaire de Grenoble.

Diário Ofícial da União (1990). O Estatuto da Criança e do Adolescente, Lei $n^{\circ} 8.069$ de 13/06/90 (16 de junho de 1990), Brasília: Autor.

Camargo, B. V. (1998). ALCESTE: um programa informático de análise quantitativa de dados textuais. Florianópolis: UFSC.

De Rosa, A. S. (1988). Sur l'usage des associations libres pour l'étude des représentations sociales de la maladie mentale. Conexions, 1(51):27-50

Degenne, A. (1985). Présentation de l'analyse de similitude. Information et Science Humaine, 15(67), 7-26.

Degenne, A., \& Vergès, P. (1973). Introduction à l'analyse de similitude. Revue Française de Sociologie, 14(4), 471-521.

Di Giacomo, J. P. (1981). Aspects méthodologiques de l'analyse des représentations sociales. Cahier Psychologie Cognitive, 1, 397-422.

Doise, W., Clemence, A., \& Lorenzi-Cioldi, F. (1992). Représentations sociales et analyses de données. Grenoble: Presse Universitaire de Grenoble.

Flament, C. (1981). L'analyse de similitude: une technique pour les recherches sur les représentations sociales. Cahier Psychologie Cognitive, 1(4), 375-95.

Flament, C. (1986a). Aspects péripheriques des représentations sociales. In C. Guimelli (Org.), Structures et transformations des représentations socials (pp. 85-118). Neuchâtel: Delachaux et Niestlé.

Flament, C. (1986b). L'analyse de similitude: une technique pour les recherches sur les représentations sociales. In W. Doise \& A. Palmonari (Orgs.), L'Étude des représentations socials (pp. 139-156). Neuchâtel: Delachaux et Niestlé.

Flament, C. (1987). Pratiques et représentations sociales. In J. L. Beauvois, R. V. Joule \& J. M. Monteil (Orgs.), Perspectives cognitives et conduites sociales. I. Théories implicites et conflits cognitifs. Cousset: DelVal.

Grize, J. B., Vergès, P., \& Silem, A. (1987). Salariés face aux nouvelles technologies. Paris: CNRS.
Jodelet, D. (1989a). Représentations sociales: un domaine en expansion. In D. Jodelet (Org.), Les représentations sociales (pp. 42-49). Paris: PUF.

Jodelet, D. (1989b). Folies et représentations sociales. Paris: PUF.

Lebart, S., \& Salem, A. (1988). L'Analyse statistique de données textuelles. Paris: Bordas.

Martin, D., \& Royer-Rastoll, P. (1990). Représentations sociales et pratiques quotidiennes. Paris: L'Harmattan.

Moscovici, S. (1976). La psychanalyse, son image et son public. Paris: PUF.

Moscovici, S. (1986). L'ère des représentations sociales. In W. Doise \& G. Palmonari (Orgs.), L'étude des représentations sociales (pp. 72-87). Neuchâtel: Delachaux et Niestlé.

Oliveira, D. C., Alvarenga, A. T., \& Siqueira, A. A. F. (1998). Práticas sociais em saúde: uma releitura à luz da teoria das representações sociais. In A. S. Paredes \& D. C. Oliveira (Orgs.), Estudos interdisciplinares de representação social (pp.49-69). Goiânia: AB Editora.

Oliveira, D. C. (2000). A educação e o trabalho infantil nos municipios de Monteiro Lobato e Santo Antônio do Pinhal. Relatório de Pesquisa apresentado à CAPES, São Paulo.

Organización Mundial de la Salud (1987). El trabajo de los niños: riesgos especiales para la salud [Série de informes técnicos 405], Washington: Autor.

Patto, M. H. S. (1996). A produção do fracasso escolar: histórias de submissão e rebeldia. São Paulo: T. A. Queiroz.

Reinert, M. (1990). ALCESTE, une méthodologie d'analyse des données textuelles et une application: Aurélia de G. de Nerval. Bulletin Méthodologie Sociologique, 28, 24-54.

Sá, C. P. (1996). Núcleo central das representações sociais. Petrópolis: Vozes.

Sá, C. P. (1998a). A construção do objeto de pesquisa em representações sociais. Rio de Janeiro: EDUERJ.

Sá, C. P. (1998b). A representação social da economia brasileira antes e depois do real. In A. S. Paredes \& D. C. Oliveira (Orgs.), Estudos interdisciplinares de representação social (pp. 49-69). Goiânia: AB Editora.

Sampaio, J. J. C., \& Ruiz, M.S.E.M. (1996, abril). Trabalho precoce e psiquismo infantil. Trabalho apresentado na Oficina sobre os impactos do trabalho precoce na saúde de crianças e adolescentes, Brasília, DF.

Vergès, P. (1984). Une possible méthodologie pour l'approche des représentations économiques. Communication-Information, 6(23), 375-98.

Vergès, P. (1992). L'évocation de l'argent: une méthode pour la definition du noyau central de la représentation. Bulletin Psychologie, 45(405), 203-209.

Vergès, P. (1998). Programas informáticos para análise de semelhanças e evocações. Aix-en-Provence: LAMES-CNRS.

Denize Cristina de Oliveira, doutora em Saúde Pública pela Universidade de São Paulo (SP), é Professora Titular da Faculdade de Enfermagem da Universidade do Estado do Rio de Janeiro (RJ). Celso Pereira de Sá, doutor em Psicologia pela Fundação Getúlio Vargas (RJ), é Professor Titular do Instituto de Psicologia da Universidade do Estado do Rio de Janeiro (RJ).

Frida Marina Fischer, doutora em Saúde Pública pela Universidade de São Paulo (SP), é Professora Titular da Faculdade de Saúde Pública da Universidade de São Paulo (SP).

Ignez Salas Martins, doutora em Saúde Pública pela Universidade de São Paulo (SP), é Professora Associada da Faculdade de Saúde Pública da Universidade de São Paulo (SP).

Liliane Reis Teixeira é mestranda da Área de Saúde Ocupacional da Faculdade de Saúde Pública da Universidade de São Paulo (SP).

Endereço para correspondência: (DCO) Rua Harmonia, 539, apto. 52A,Vila Madalena, 05435-000, São Paulo, SP. 